\title{
Inequalities in the London bicycle sharing system revisited: impacts of extending the scheme to poorer areas but then doubling prices
}

\author{
Anna Goodman, ${ }^{\mathrm{a}}$ James Cheshire ${ }^{\mathrm{b}}$
}

${ }^{a}$ Faculty of Epidemiology and Population Health, London School of Hygiene and Tropical Medicine, London, WC1E 7HT, UK

${ }^{\mathrm{b}}$ Centre for Advanced Spatial Analysis, University College London, Gower Street, London WC1E 6BT, UK

Corresponding author: Anna Goodman, London School of Hygiene \& Tropical Medicine, Keppel Street, London, WC1E 7HT, UK (anna.goodman@1shtm.ac.uk).

Note: this is a personal version, created by Anna Goodman, of the text of the accepted journal article. It reflects all changes made in the peer review process, but does not incorporate any minor modifications made at the proof stage. The complete citation for the final journal article is:

- Goodman, A \& Cheshire, J. 2014. Inequalities in the London bicycle sharing system revisited: impacts of extending the scheme to poorer areas but then doubling prices. Journal of Transport Geography, 41, 272-279.

- DOI: $10.1016 / \mathrm{j} . j$ trangeo.2014.04.004

Copyright (C) and Moral Rights for this paper are retained by the individual authors and/or other copyright owners 


\begin{abstract}
$\underline{\text { Abstract }}$
Cycling confers transport, health and environmental benefits, and bicycle sharing systems are an increasingly popular means of promoting urban cycling. Following the launch of the London bicycle sharing system (LBSS) in 2010, women and residents of deprived areas were under-represented among initial users. This paper examines how the profile of users has changed across the scheme's first three years, using total-population registration and usage data. We find that women still make fewer than $20 \%$ of all 'registered-use' LBSS trips, although evidence from elsewhere suggests that the introduction of 'casual' use has encouraged a higher overall female share of trips. The proportion of trips by registered users from 'highly-deprived areas' (in the top tenth nationally for income deprivation) rose from $6 \%$ to $12 \%$. This was due not only to the 2012 LBSS extension to some of London's poorest areas, but also to a steadily increasing share of trips by residents of highly-deprived areas in the original LBSS zone. Indirect evidence suggests, however, that the two-fold increase in LBSS prices in January 2013 has disproportionately discouraged casual-use trips among residents of poorer areas. We conclude that residents in deprived areas can and do use bicycle sharing systems if these are built in their local areas, and may do so progressively more over time, but only if the schemes remain affordable relative to other modes.
\end{abstract}

Keywords: Bicycle sharing system; inequalities; gender; socio-economic position; London

\title{
Highlights
}

- The London bicycle sharing system has been well-used over its first 3 years

- Women still make $<20 \%$ of registered-use trips, but a higher share of casual trips

- The share of 'deprived' users doubled, partly as the scheme expanded to poorer areas

- A recent price rise may, however, have partly offset the benefit of this expansion

- Bicycle sharing systems may need to be local and affordable to attract poorer users 


\section{Introduction}

Successfully promoting cycling is expected to confer important transport, health and environmental benefits (de Hartog et al., 2010; Maizlish et al., 2013; Woodcock et al., 2013). Cycling for transport is one way to integrate physical activity into daily life (WHO, 2002), and can also reduce pollution and ease congestion by displacing journeys that would otherwise have been made by motorised modes. Creating opportunities for such active travel has therefore been identified as one central feature of a 'healthy city' (Rydin et al., 2012). Similarly, cycling for recreation can also provide an important source of physical activity, and appears less likely than other forms of recreational physical activity to involve motorised travel (e.g. due to driving to a walking route or sports centre) (Goodman et al., 2012).

The growing number of bicycle sharing systems (BSS) around the world provide increased urban opportunities for both cycling for transport and cycling for recreation (Fishman et al., 2013; O'Brien et al., 2014). For example, the London bicycle sharing system (LBSS) is particularly well-used for commuting trips (Transport for London, 2011a), including multi-modal trips starting from major train stations (O'Brien et al., 2014; Wood et al., 2011; Zaltz Austwick et al., 2013). Using LBSS is also popular as a leisure activity, with operational and observational research both indicating comparatively high level of use around London's large parks (Goodman et al., 2014; Zaltz Austwick et al., 2013). By increasing access to bicycles for such trips, LBSS and other such schemes facilitate cycling directly, and health impact modelling confirms the net health benefits that this confers upon BSS users (Rojas-Rueda et al., 2011; Woodcock et al., 2014). Moreover, because BSS users are much less likely than personal-bicycle users to wear helmets or 'cycling' clothes, BSS may indirectly encourage cycling by normalising the image of cycling as an everyday activity (Fischer et al., 2012; Fishman et al., 2013; Goodman et al., 2014).

The introduction of a BSS in London might therefore seem one promising intervention to achieve the Mayor of London's vision of making cycling “something anyone feels comfortable doing, [including people] of all ages, races and backgrounds, and in all parts of London" (Greater London Authority, 2013, p.9). In practice, however, LBSS did not initially seem likely to reduce the gender and socio-economic inequalities in cycling participation which have been raised as a cause of concern (Marmot, 2010; Steinbach et al., 2011). Instead in the first seven months of the scheme's operation (July 2010 to February 2011), LBSS use was even more male-dominated than cycling in London in general, with $82 \%$ of LBSS trips made by men (Ogilvie and Goodman, 2012). Individuals living in income-deprived areas were also underrepresented, a pattern in line with the general tendency for London's cyclists to be drawn from more affluent households or neighbourhoods (Goodman, 2013; Steinbach et al., 2011). Similar findings with respect to the socio-economic advantage of BSS users have also been reported in Washington DC (LDA Consulting, 2012; Virginia Tech, 2012) and Montreal (Fuller et al., 2011), although the overrepresentation of males was only observed in Washington. 
One interesting finding in London, however, was that trip rates among registered users were in fact higher among residents in poorer areas after one adjusted for the fact that these poorer areas were less likely to be near an LBSS docking station (Ogilvie and Goodman, 2012). This raised the possibility that the share of trips made by residents from more deprived areas would increase following the (then future) extension of LBSS in March 2012 to some of the poorest parts of London. On the other hand, in January 2013 LBSS doubled its prices, making the cost of a single cycle trip (£2) more expensive than a single bus trip ( $£ 1.40$ with a pre-paid card). This development might plausibly be expected to operate in the opposite direction, and disproportionately discourage LBSS use among those living in more deprived areas.

This paper therefore revisits the important question of how far LBSS is contributing to the realisation of the wider policy aim to encourage cycling among a broad variety of Londoners. Specifically, it examines how the gender and, in particular, the socioeconomic profile of LBSS users has been affected by 1) the geographic extension of LBSS to East London and 2) the doubling of LBSS prices. To contextualise these findings, this paper also provides a broader update of usage of LBSS over its first three years. Besides addressing a question of local policy relevance, this paper contributes to the international BSS evidence base by providing (to our knowledge) the first examination of the effect of changes in spatial extent or pricing upon the profile of BSS users in any city. Such evidence is of value since many of the other 600 BSS in operation globally may in the future also wish to consider making such changes, particularly since most of these schemes have been completed only in the past 5 years (Meddin and DeMaio, 2013).

\section{$\underline{2 \text { Methods and context }}$}

\subsection{The London bicycle sharing system (LBSS)}

LBSS was launched by the public body Transport for London on 30th July 2010. The scheme's bicycles can be taken from any docking station and returned to any other docking station, with the scheme operating 24 hours a day, 365 days a year. To hire a bicycle, users can either register online for an access key using a UK credit/debit card ('registered use', minimum age 18), or else pay by at docking stations by a UK or international credit/debit card ('casual use', available since $3{ }^{\text {rd }}$ December 2010). Users initially pay for access to LBSS bicycles, after which trips of under 30 minutes are free but longer trips incur additional usage charges at a progressively faster rate. Access initially cost $£ 1$ for 1 day, $£ 5$ for 7 days, and $£ 45$ for 1 year: from $1^{\text {st }}$ January 2013 , these prices doubled.

The scheme initially comprised 5000 bicycles located across 315 docking stations, spread at approximately $300 \mathrm{~m}$ intervals across $45 \mathrm{~km}^{2}$ of central London. This original zone included the entertainment centre of the West End, the business district of the City of London, and the leisure areas of Hyde Park and Regent's park. It also included some more affluent residential areas to the west and some more deprived residential areas to the east. On $8^{\text {th }}$ March 2012 the scheme extended east to cover a larger area and 
incorporate 8000 bicycles at 575 docking stations across $65 \mathrm{~km}^{2}$ (Figure 1). The expanded scheme now encompasses the prosperity of the Canary Wharf business district in Docklands, characterised by city commuters working in financial services. It also encompasses much more of London's relatively deprived East End, including the poorquality, high-density housing of London's poorest borough, Tower Hamlets. An expansion in any other direction would not have incorporated a potential user base with such contrasting socio-economic characteristics, and this eastern extension therefore presents an interesting 'natural experiment' in terms of examining the type of users attracted by this newly-expanded BSS. 
Figure 1: The London Bicycle Sharing System's original zone and eastern extension relative to background levels of income deprivation

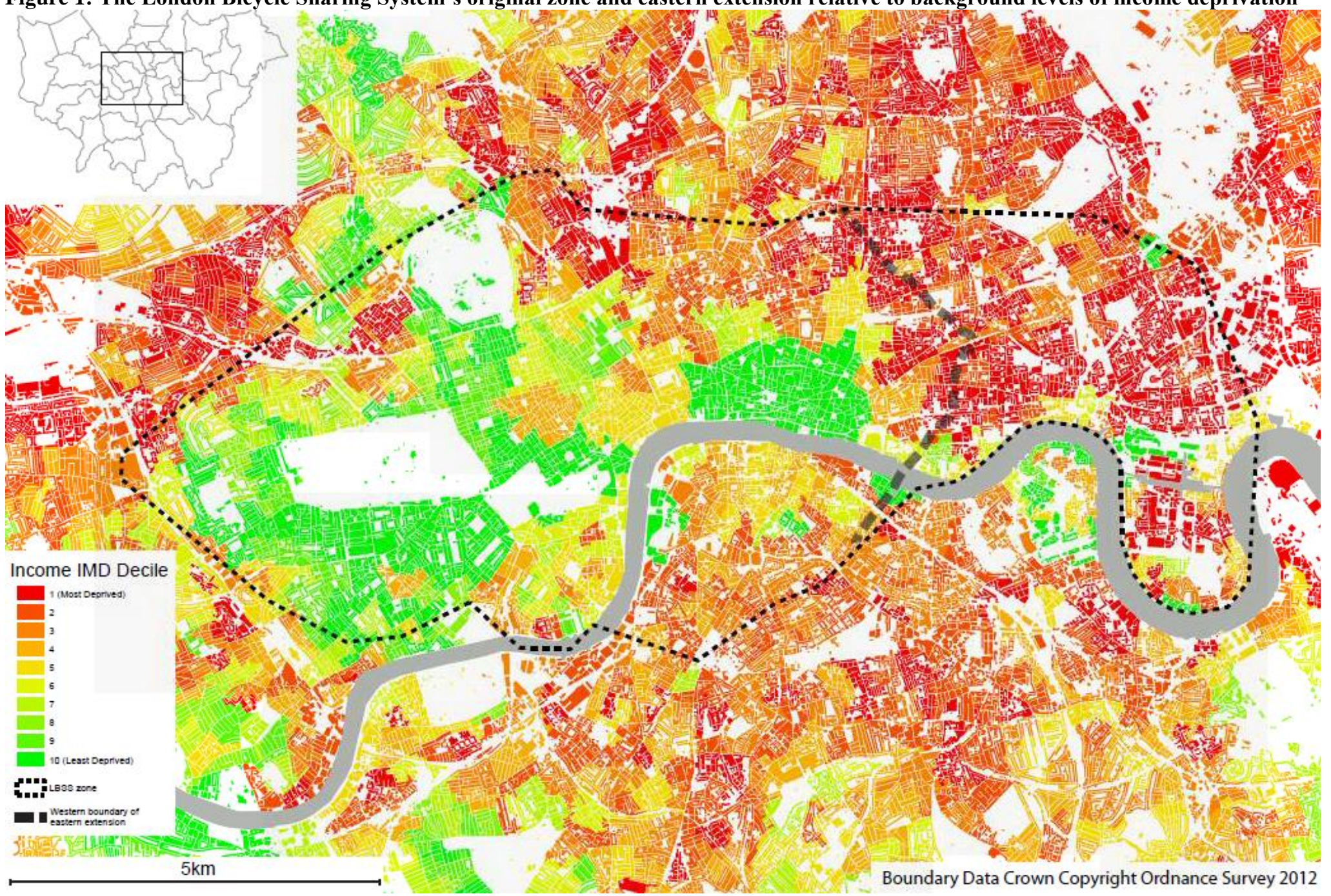

Building outlines have been used to emphasise the parks and road layout of London. The LBSS zone boundary has been defined as an approximate convex hull around the docking stations. 
Still more recently, on $13^{\text {th }}$ December 2013, LBSS expanded again to include additional areas of southwest London. This, however, occurred after the time period considered in this paper.

\subsection{Operational registration and usage data}

Transport for London provided operational usage data for all trips made between $30^{\text {th }}$ July 2010 and $31^{\text {st }}$ July 2013. Of these, we excluded $0.1 \%$ missing data on the date on which the trip took place. For all remaining trips, the start date was available plus a unique ID number linking trips made by registered users on the same LBSS access key or made by casual users on the same debit/credit card. For registered users, this unique ID was also linked to anonymised operational registration data. In this registration data, individuals' titles and/or first names were used to assign gender, and home postcodes (mean population 50 individuals) were used to assign area of residence. No individuallevel data was available on the characteristics of casual users.

From $1^{\text {st }}$ April 2011 onwards, the available trip-level information additionally included the start and end docking station of the trip, and the start and end time of the trip (in seconds). We excluded from our analyses the $0.4 \%$ of trips with the same start and end station and lasting less than 2 minutes, assuming that no trip had in fact been made. For all trips, we identified whether the trip started or ended (i) in London's large Hyde Park or Regent's Park, or (ii) serving one of London's ten largest railway stations. For each registered-use trip, we also calculated the minimum crow-flies distance from the centroid of the home postcode to the start or end docking station (whichever was nearest). Ethical approval for the study was granted by LSHTM ethics committee (reference 6474).

\subsection{Small-area income deprivation of individuals and of docking stations}

We assigned small-area deprivation at the level of Lower Super Output Areas (LSOA) using the 2010 English Indices of Multiple Deprivation (DCLG, 2011). These widelyused geodemographic measures rank each LSOA (represting a population of approximately 1500) according to 38 different indicators grouped into seven domains of deprivation, including income, employment, education and crime. Each LSOA is thus assigned an overall deprivation rank and also a rank for each of these seven domains. Following official publications (DCLG, 2011), we defined 'highly-deprived' areas as being those ranked in the top tenth nationally for overall deprivation, and also created a second measure of those ranking in the top tenth for income deprivation. These two deprivation measures yeilded very similar patterns of results, and so we present results for the income deprivation score to maximise comparability with previous research (Ogilvie and Goodman, 2012).

We had no direct information about the deprivation levels of casual users. To examine impacts indirectly, we calculated a deprivation score for each docking station, calculating this as the mean deprivation rank of registered users starting trips from that station. We then examined how casual use of more versus less 'deprived' stations changed over time, 
assuming that the stations used most often by registered users from poorer areas will also tend to be the stations used most often by casual users from poorer areas.

\subsection{Geographic and comparative analyses}

Most analyses rely on the presentation of raw trip frequencies or raw percentages (e.g. percentage of trips made by females). Binomial proportion confidence intervals were calculated around percentages but are not presented in the graphs as they are too narrow to be visible (typically $+/-0.1$ percentage point). When examining the association between registered user characteristics and trip rates, we excluded the $0.6 \%$ of trips made by individuals with missing data on gender $(0.001 \%)$ or postcode $(0.08 \%)$, or with nonEnglish postcodes $(0.5 \%)$.

To compare registration rates across areas, we compared the number of registered LBSS members with small-area population counts from the 2011 UK Census. We made this comparison by summing the number of LBSS users in each Output Area (OA) - the smallest census geographic reporting unit available - and using the location quotient (LQ) to identify those OAs with a larger number of registered users than one would expect given their resident population. The LQ is a commonly used spatial measure (originating in economic geography) since it has the advantage of normalising by both the total population size and by the population size in each small area. It was calculated as follows:

$$
\mathrm{LQ}=\frac{(\text { No. LBSS users in OA }}{\text { (Population of OA }} \frac{/ \text { Total no. LBSS users in London })}{/ \text { Total population of London })}
$$

Where OAx is a particular Output Area of interest. LQ values of less than one suggest fewer users than expected whilst values greater than one suggest more than expected. We also sought, briefly, to compare whether non-London LBSS users were more likely than the general population of inter-city commuters entering the LBSS zone to come from Oxford and Cambridge, Britain's leading cycling towns (Goodman, 2013). For this, we used 2010 and 2011 data from the Annual Population Survey, an annual nationallyrepresentative sample of approximately $1 \%$ of the working population (Annual Population Survey, 2013). We used Stata 12.1 for statistical analyses and used the R Project for Statistical Computing and Graphics (R Core Team, 2012) for visualisation.

\section{$\underline{3 \text { Results }}$}

\subsection{Current patterns of LBSS usage}

\subsubsection{Levels of LBSS registration and usage}

Across the scheme's first three years, 152,000 registered users made 15.93 million trips on LBSS; a further 35,000 individuals registered for LBSS but made no recorded trips. Considering all registered users, including those who made no trips, the registration rate for LBSS was $13.6 \%$ in the area where the scheme was first launched, $5.4 \%$ in the new 
eastern extension, and $2.3 \%$ for London as a whole (see Figure 2). A further 1.4 million casual users made 7.14 millions trips, generating a total of 23.07 million trips across users of all types (21,000 per day). Figure 3 displays the spatial distribution of these trips across the LBSS zone in the third year of the scheme's operation, and reveals somewhat lower overall levels of use in the eastern extension than in the original zone. As Figure 3 also shows, docking stations in the eastern extension zone were more likely to show a fairly even split between registered and casual users; overall, casual users made $44 \%$ of trips starting in the eastern zone in the scheme's third year vs. $35 \%$ in the original zone.

Figure 2: Location quotient for LBSS registration rates (June 2010 - July 2013)

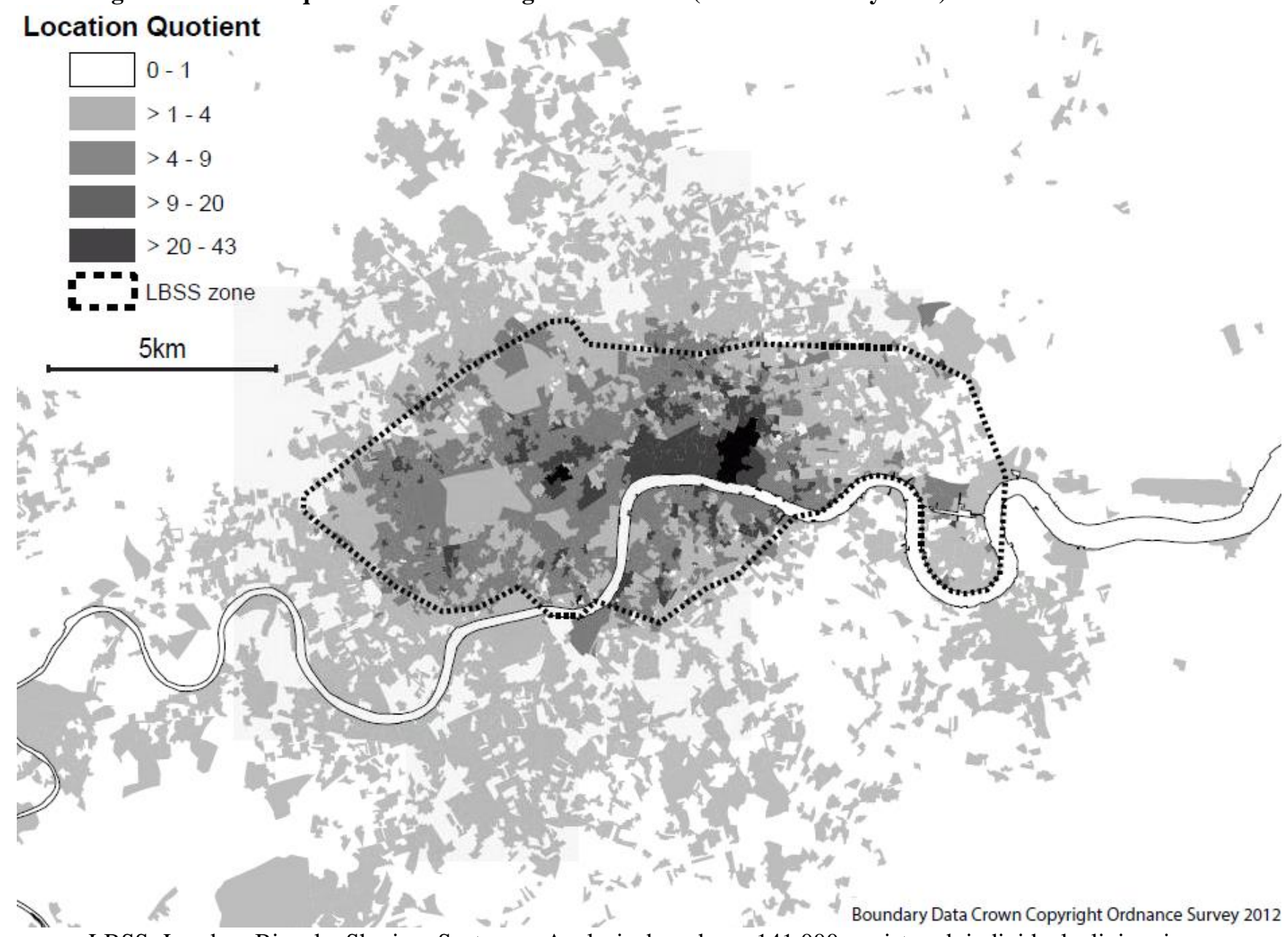

LBSS=London Bicycle Sharing System. Analysis based on 141,000 registered individuals living in London. 
Figure 3: Volume and type of LBSS docking station usage (August 2012-July 2013)

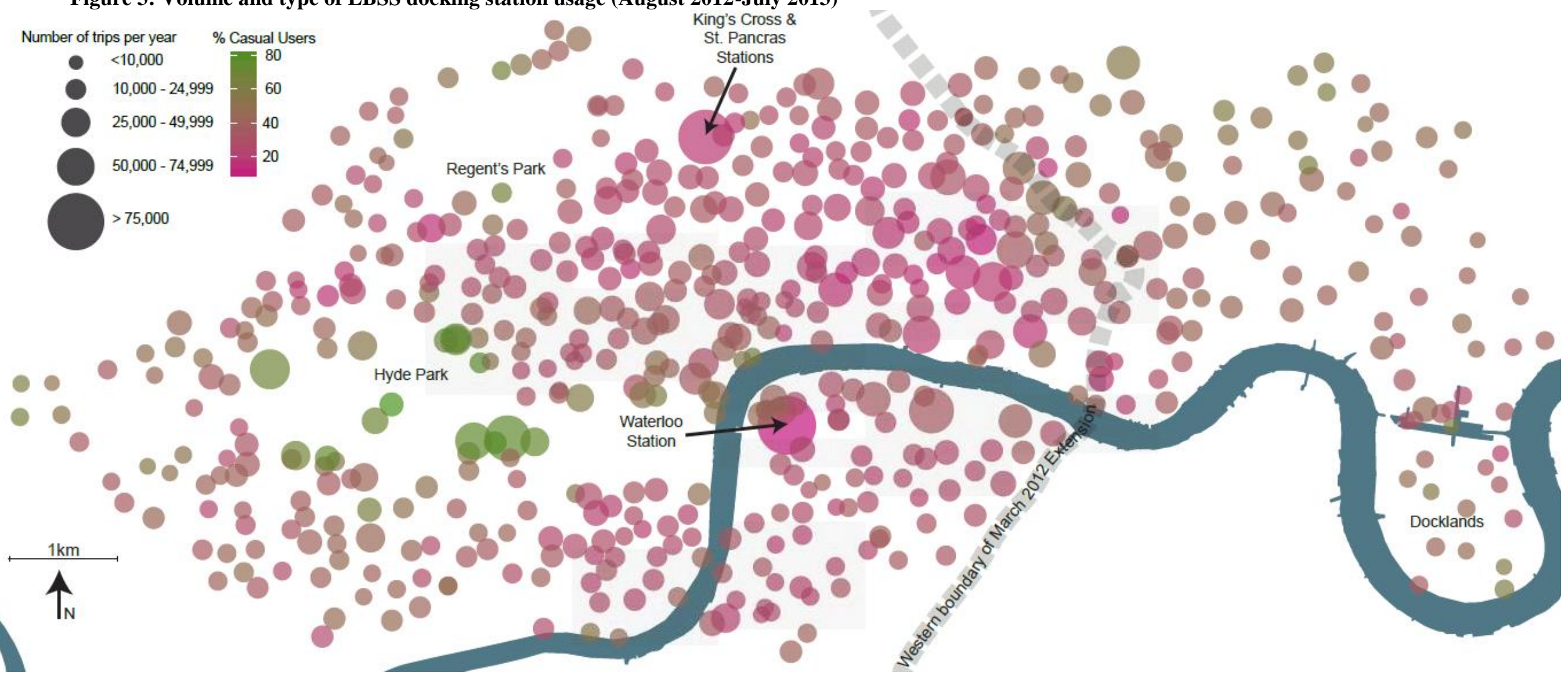

LBSS=London Bicycle Sharing System. The map shows the number of trips starting from each station in the previous 12 months, and is based on 9.0 million trips by 72,000 registered users and 614,000 casual users. 


\subsubsection{Commuter trips and park trips: marked differences by gender and area deprivation}

Figure 3 confirms that, as other researchers have previously described in more detail (O'Brien et al., 2014; Zaltz Austwick et al., 2013), a comparatively high number of LBSS trips start or end near large railway stations (particularly trips by registered users), or in one of London's large parks (particularly trips by casual users). The high prevalence of multi-modal commuting via large railway stations resulted in a bi-modal distribution of trip distance from the users' home, with additional smaller peaks corresponding to major English cities (Figure 4, top part).

While it is perhaps not surprising that the highest usage levels are seen among those living near to a docking station, the bi-modal shape of the distribution is noteworthy. This distribution illustrates the popularity of LBSS with longer distance commuters, and also appears to be influenced by the popularity of cycling in the home towns/cities of these commuters. For example, residents of England's two leading cycling towns, Cambridge and Oxford, made $2.1 \%$ of these non-Londoner LBSS trips, three times as many as expected given their $0.7 \%$ share of all commuters into London. We suggest that one implication of this usage pattern is that Transport for London should consider further marketing of the scheme beyond London, since commuter towns represent a large potential user group during the week possibly also for leisure use at weekends. By contrast, the reduced scheme usage from those living beyond walking distance to a docking station but within the London transport system suggests that Londoners are relatively unlikely to take alternative forms of local public transport to or from their nearest docking station in order to cycle part of the journey. 
Figure 4: Distribution of minimum distance between registered users' homes and their LBSS trips, and average demographic characteristics of users making trips at different distances (August 2012July 2013)

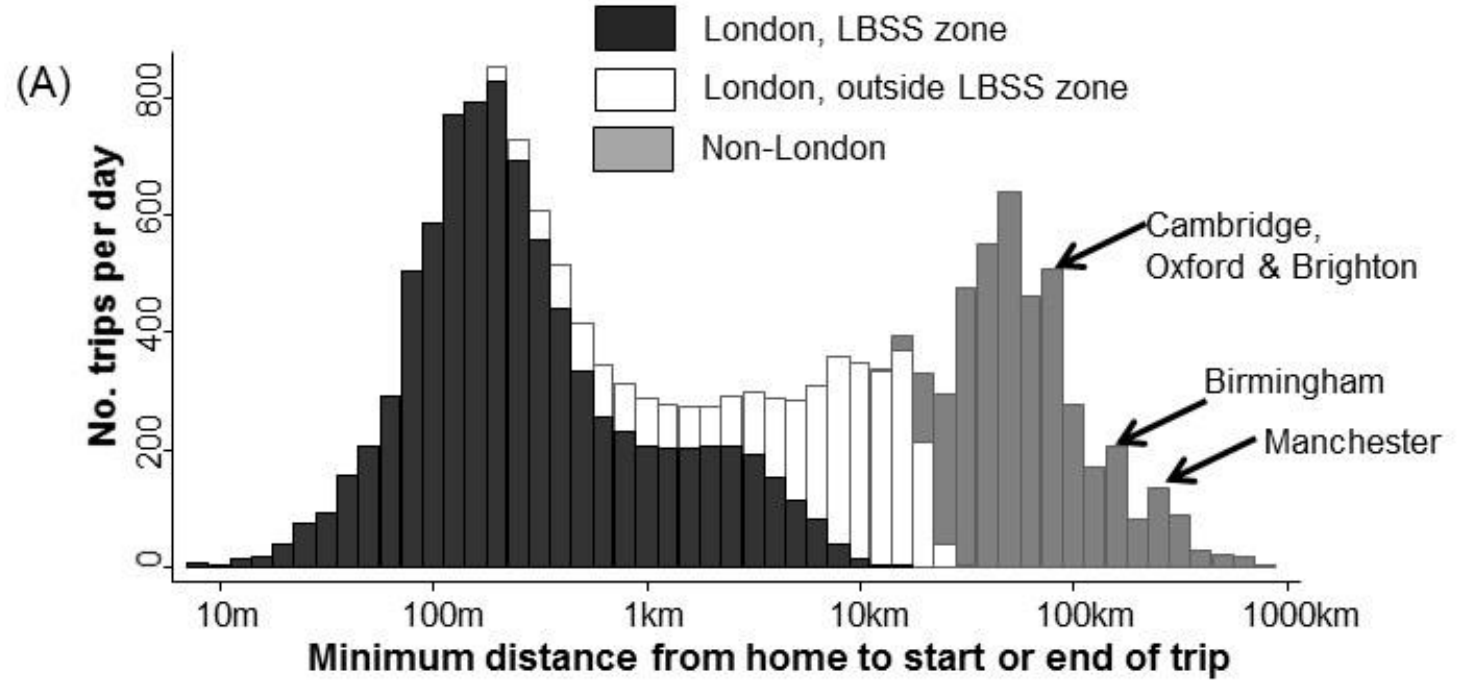

(B)

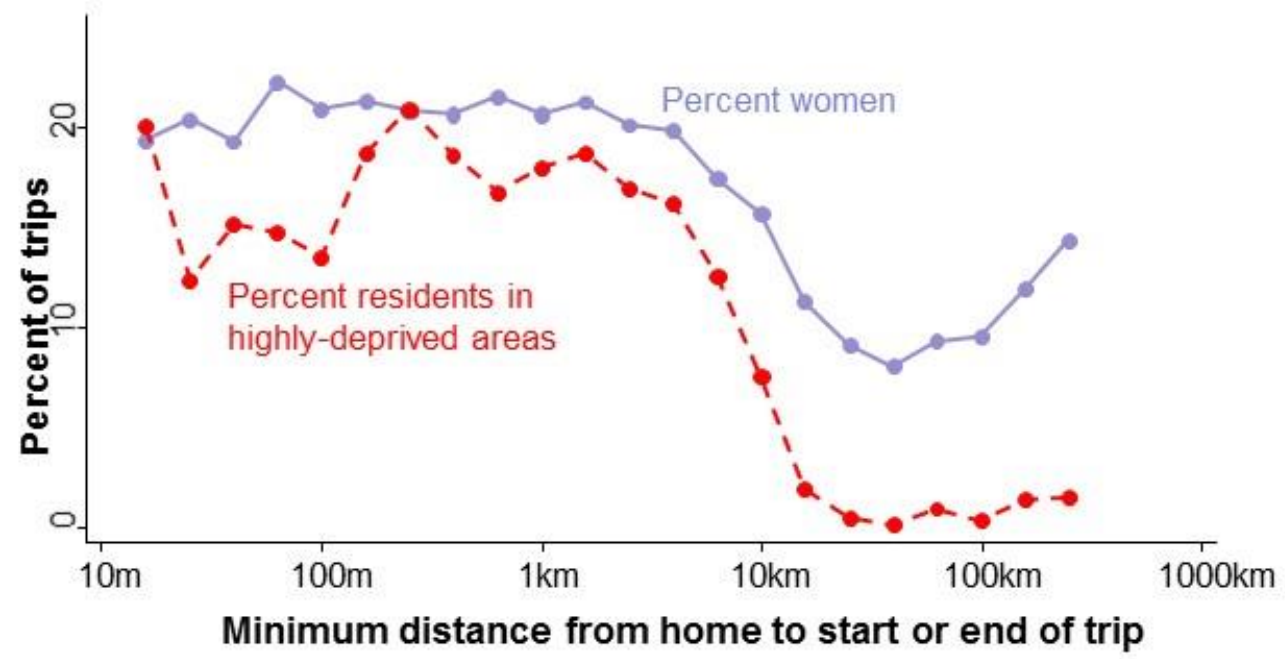

LBSS=London Bicycle Sharing System. Analysis based on 5.7 million trips by 72,000 registered users between August 2012 and July 2013. Confidence intervals not presented as these are generally too narrow to see.

The proportion of registered-use trips made by women was lower among non-Londoners than among Londoners (Figure 4, part B), in line with other recent research indicating that women were less likely than men to show a 'commuting' pattern of LBSS use (Beecham and Wood, 2014). This difference in usage plausibly reflects the fact that women are less likely than men to commute long distances by high-speed modes such as the train (Lyons and Chatterjee, 2008), and suggests one reason for the surprisingly low share of all LBSS trips made by women (Ogilvie and Goodman, 2012). The proportion of registered-use trips made by individuals from highly-deprived areas was also far lower among non-Londoners (Figure 4, part B), while the proportion of trips made by residents in affluent areas was correspondingly greater (e.g. 55\% of non-Londoner trips were made by residents in the most affluent quarter of areas vs. $18 \%$ of Londoner trips). As for the 
large number of trips starting in London's major parks (Figure 3), these were most common among casual users (15\%) and rarest among non-London registered users (2\%). Among registered users living in London, park trips were more substantially more common among women and among residents in more affluent areas (Figure 5).

Figure 5: Proportion of LBSS trips starting or ending in parks, among registered users living in London (August 2012-July 2013)

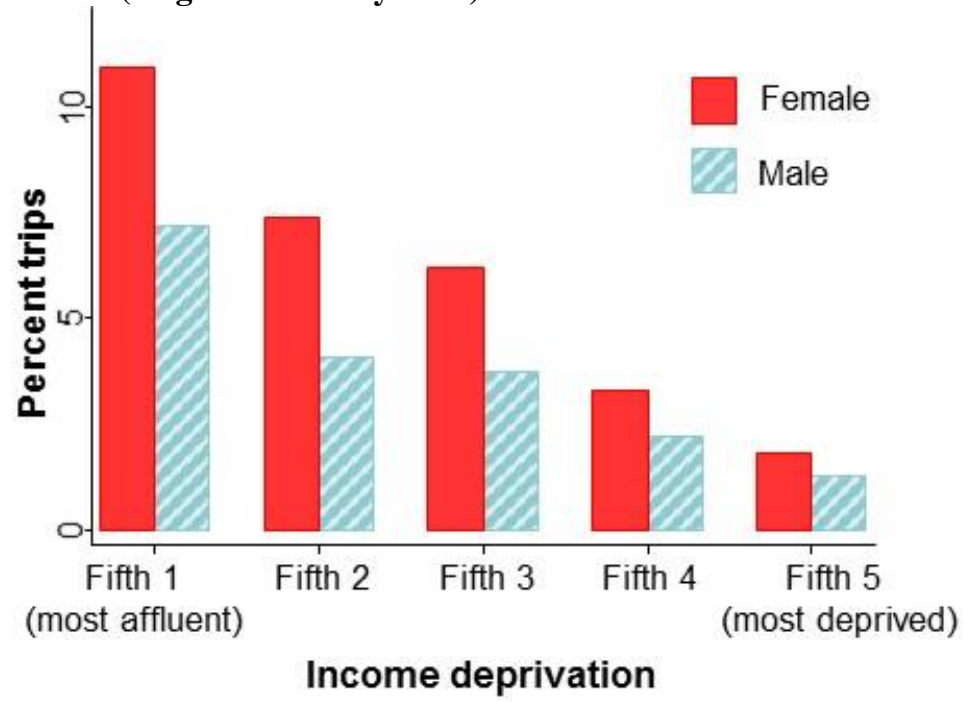

LBSS=London Bicycle Sharing System. Analysis based on 4.2 million trips by 54,000 registered users between August 2012 and July 2013. Fifths of area deprivation defined using national quintiles.

Confidence intervals not presented as these are too narrow to be clearly visible.

\subsection{Changes over time in LBSS use and in the LBSS user profile}

\subsubsection{Trends in numbers of LBSS trips}

Despite marked seasonal variation, the number of LBSS trips generally increased from 2010 to 2012, reflecting the continuation of high levels of use by registered users across this time plus a growing proportion of use by casual users (Figure 6). Following the price increase in January 2013, the number of registered user trips continued to increase slightly (7\% increase relative to the equivalent seven-month time period in 2012) but the number of casual user trips decreased (14\% decrease). 
Figure 6: Average number of registered and casual trips per day over the first three years of the London Bicycle Sharing System

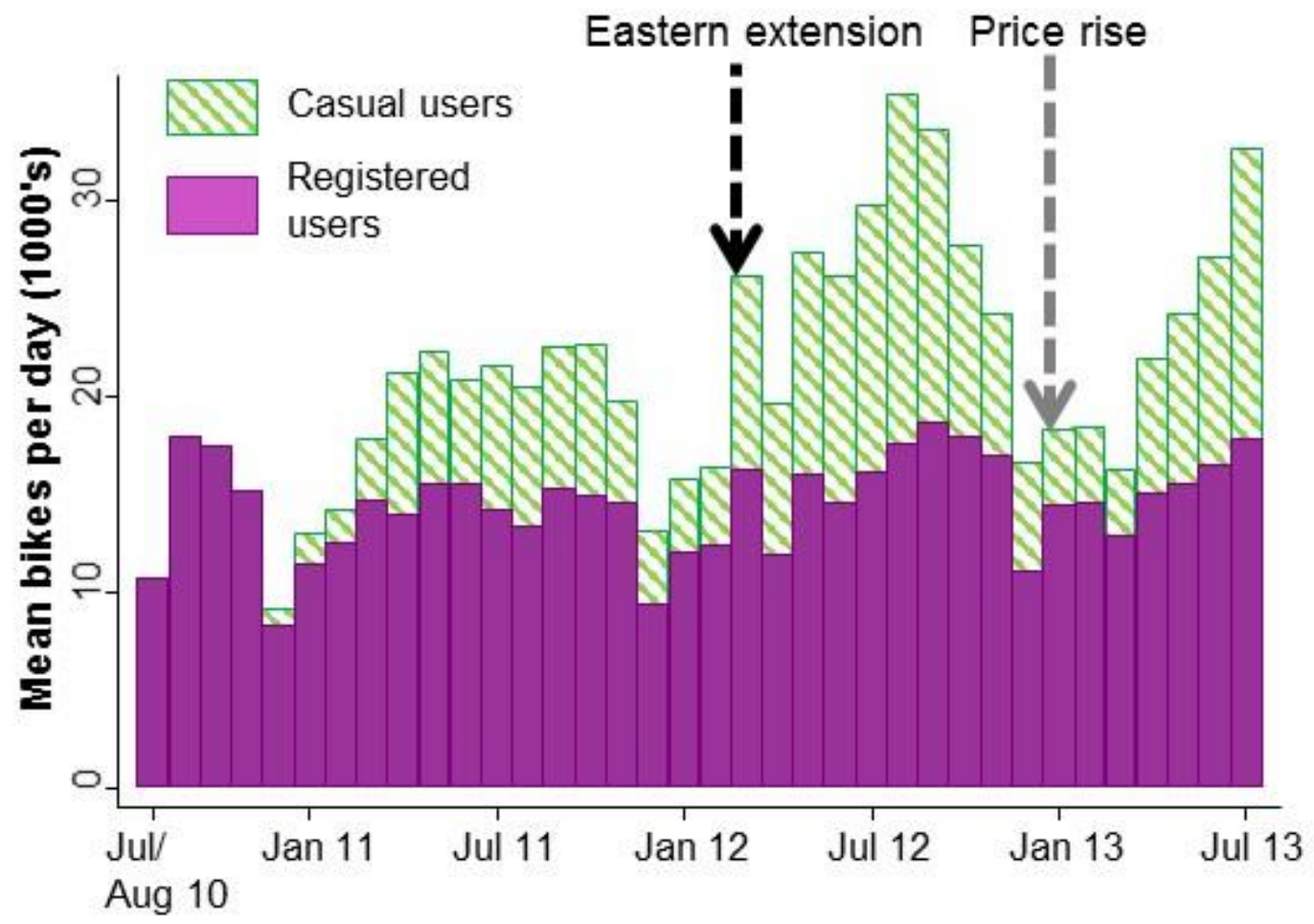

\subsubsection{Trends in the demographic and socio-economic profile of registered users}

Among registered users, the percentage of trips made by women remained low, ranging from $15.9 \%$ to $19.5 \%$ across all months in the study period (Figure 7, part A). Indeed, there was even a small decline in this proportion across the three years, from a mean of $18.5 \%$ in the first year, to $18.2 \%$ in the second year and $17.1 \%$ in the third year (standard error $0.02 \%$ for all three proportions). There was, however, no clear change in the pace of this gradual downward trend following either the eastern expansion or the price rise. 
Figure 7: Proportion of registered LBSS trips made by women and people living in highly-deprived areas (top), including stratification of the trips made by residents of highly-deprived areas according to their area of residence (bottom)

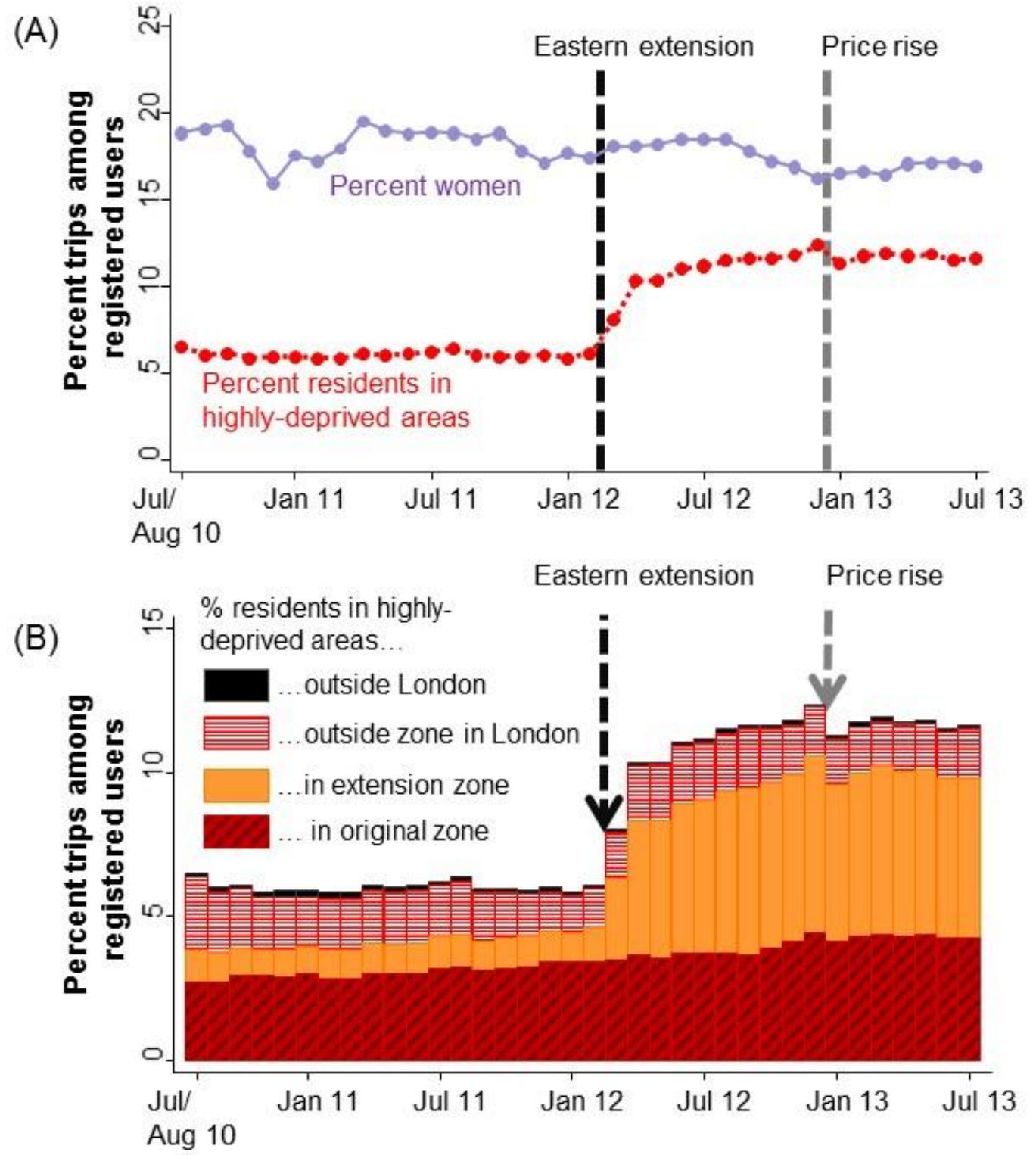

LBSS=London Bicycle Sharing System. Analysis based on 15.8 million trips by 151,000 registered users between July 2010 and July 2013. Confidence intervals not presented as they are in all cases narrower than the dots marking each month

Following the eastern extension, the proportion of registered users from highly-deprived areas doubled from around 6\% prior to March 2012 to 10-12\% thereafter (Figure 7, part A). This increase was seen to a similar degree in both sexes, rising from $6 \%$ to $11 \%$ in males, and from $7 \%$ to $12 \%$ in females. These marked increases were driven by a fivefold increase in the proportion of all registered LBSS trips made by residents of highlydeprived areas in the new eastern extension zone (Figure 7, part B). The proportion of trips made by residents of highly-deprived areas in the original LBSS zone was not 
noticeably affected by the extension, but did show a more modest steady increase across the entire study period from $2.9 \%$ in 2010 to $4.3 \%$ in 2013. Following these increases, individuals from poorer areas were only slightly underrepresented relative to their share of the local population. For example, people living in highly-deprived areas represented $12 \%$ of adult residents in the original LBSS zone and made $10 \%$ of the trips by those residents in 2013. In the eastern extension, the corresponding values were $56 \%$ vs. $53 \%$.

There was little suggestion of any change in the proportion of registered users living in deprived areas in the seven months following the price rise (Figure 7).

\subsubsection{Likely trends in the socio-demographic profile of casual users}

No direct evidence is available regarding the demographic profile of casual users.

Nevertheless, the eastern extension zone undoubtedly covered a more deprived area of London (Figure 1), and this was reflected in the characteristics of its registered users (e.g. $41 \%$ of registered users starting a trip in the eastern zone since March 2012 lived in highly-deprived areas, versus $7 \%$ in the original zone). Moreover, casual use made up a higher share of total LBSS trips in the eastern extension (Figure 3) and there was also a positive correlation between a station's deprivation ranking and the proportion of casual trips starting from that station $(\mathrm{r}=0.17, \mathrm{p}<0.001)$. As such, it seems highly likely that the proportion of casual users from more deprived areas increased following the eastern extension, and it is plausible that this occurred to an even more marked degree than was the case for registered users.

As for the likely effect of the price rise, Figure 8 presents the proportion of all a) registered use trips and b) casual use trips made from 'highly-deprived' stations, operationalised as stations in the top tenth in terms of the mean deprivation levels of their registered users. The pattern was very similar in sensitivity analyses which instead operationalised 'highly-deprived' stations as those which were in the top quarter or the top half for deprivation. For registered users, the pattern was very similar to that seen in Figure 7, which is reassuring in terms of suggesting that station deprivation can be a valid proxy for area-of-residence deprivation. For casual users, the proportion of trips from highly-deprived stations was stable prior to the price increase but then decreased thereafter. This therefore provides indirect evidence that the overall declines in casual use observed after the price increase in January 2013 may have disproportionately occurred among users living in poorer areas. 
Figure 8: Proportion of registered and casual LBSS trips starting from 'highly-deprived' stations

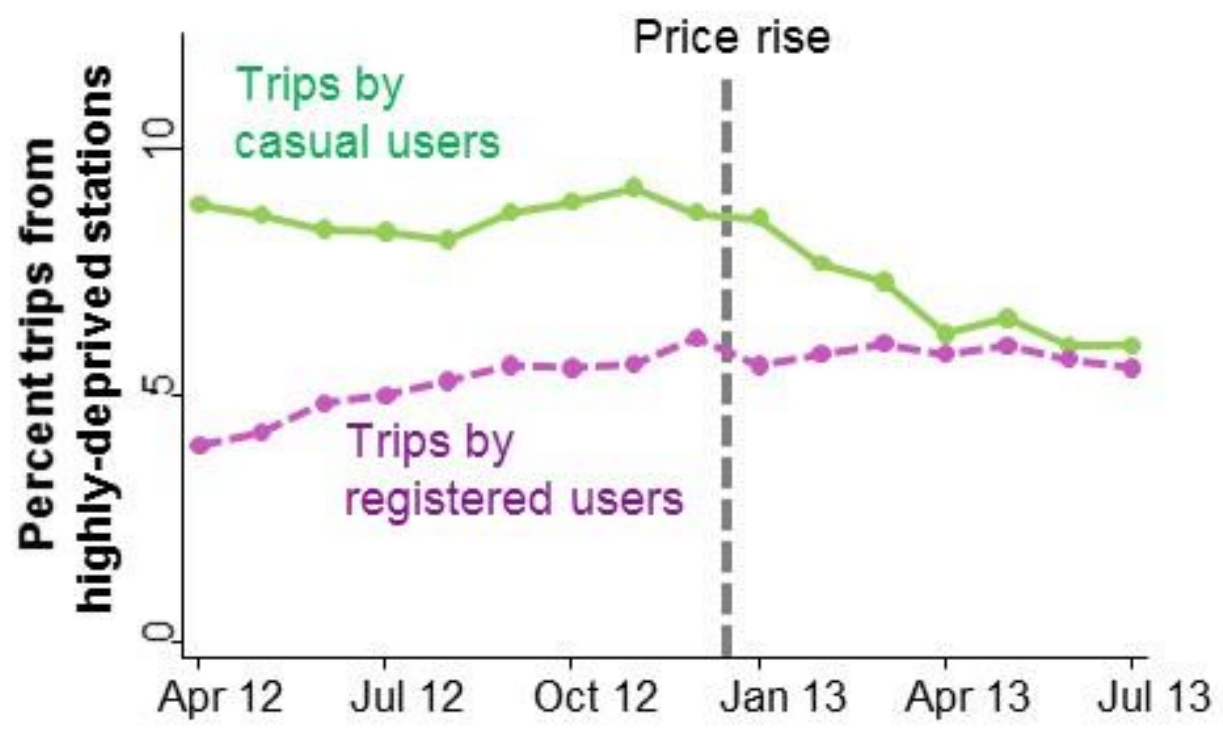

LBSS=London Bicycle Sharing System. Analysis based on 12.1 million trips by 831,000 users between April 2012 and July 2013. Analysis restricted to period from April 2012 onwards when almost all stations were fully operational: almost all of the 'highly-deprived' stations were in East London, so before April 2012 usage of these stations was necessarily zero. Confidence intervals not presented as they are in all cases narrower than the dots marking each month

\section{Discussion}

\subsection{LBSS usage by women}

Although women continue to make only a small minority of registered-use trips (under $20 \%$ ), this needs to be set in the context of other sources of observational and survey data which suggest that women constitute a higher share of casual users (e.g. estimated at $37 \%$ in July 2011 (Transport for London, 2011a)). This is likely to explain why a recent direct observational study reported that the overall proportion of women among LBSS cyclists was actually somewhat higher than among personal-bicycle cyclists (32\% vs. 23\%) (Goodman et al., 2014). In addition, it is noteworthy that women are particularly likely to use LBSS to cycle in London's large parks (see also Beecham and Wood, 2014), given that acquiring skills as a leisure cyclist may be an important first step in taking up cycling for transport (Nettleton and Green, In press). As such, although women continue to make far fewer than half of LBSS trips, LBSS may now be tending to increase rather than decrease the overall share of female cyclists in London.

\subsection{LBSS usage by residents in highly-deprived areas}

Despite prior media characterisation of LBSS as a "posh-boy toy" (The Guardian, 2011), residents in London's highly-deprived areas did use the scheme when it extended outside of central London to cover some of London's poorest areas. This is reassuring insofar as it indicates that the extension was not, for example, exclusively used by affluent professionals to cross East London and reach the financial centre of Canary Wharf. 
Instead, our work suggests that residents in highly-deprived areas can and do use bicycle sharing systems if these are built in their local areas - and that this local access is important because very few individuals from deprived areas regularly commute into London from the outside (cp. Lyons and Chatterjee, 2008). Thus to the extent that BSS schemes are used by inter-city commuters they may disproportionately serve more affluent individuals, but to the extent that they are used by local residents they may serve richer and poorer individuals to a more similar degree.

In addition, the growing share of users living in highly-deprived areas in the original LBSS zone suggests the potential for such schemes to become more equitable over time. This plausibly partly reflects a widespread tendency for more affluent individuals to be 'early adopters' of new technologies (Rogers, 1962, 1986). More speculatively, LBSS may have been particularly visible to poorer local residents once it was established because such residents make more trips at street level by foot or by bus, rather than by the London underground (Transport for London, 2011b). Yet despite becoming more equitable, LBSS continues to be used somewhat less often by residents in highlydeprived areas than one would expect given their share of the London population. This may partly reflect the exclusion of some of London's poorest residents because they do not have the credit/debit card necessary to use the scheme. It may also partly reflect the tendency for poorer individuals to engage less often in recreational physical activities (Beenackers et al., 2012), a tendency which this research suggests may include making LBSS trips in London's large parks.

Finally, we found that although the socio-economic profile of registered users appeared little affected by the price rise in January 2013, poorer casual users may have disproportionately reduced their usage of the scheme. It is plausible that the fact that a single LBSS trip now costs more than a single, adult bus trip ( 22 vs. £1.40) is particularly off-putting for low-income individuals making occasional, ad hoc trips on the bicycles. Given the net health benefits of BSS use (Rojas-Rueda et al., 2011; Woodcock et al., 2014), the modest-to-moderate decreases in LBSS trip rates following the price rise may have had some negative effect on both health and health equity in London.

\subsection{Limitations and directions for future research}

Our access to total-population usage data, and our ability to link registered users to their registration data, allowed us to characterise patterns of LBSS use with high precision and with low risk of selection bias. The registration data available to us was very limited, however, and lacked such basic demographic variables as age or ethnicity. There is also likely to be some measurement error in our assignment of gender and area of residence, as some registered users will have given or lent their LBSS access key to other individuals for at least some trips. We believe, however, that most registered members will have been discouraged from lending their keys to others by the fact that the registered member remains the person liable for substantial fines $(£ 150-£ 300)$ if the bicycle is lost, damaged or kept out for more than a few hours. A third important limitation is that our lack of individual-level measures of socio-economic position renders this study liable to ecological bias; for example, we cannot discount the 
possibility that the growth in LBSS usage among residents in highly-deprived areas was driven by a small number of more affluent people within those areas, or by other atypical groups such as students.

As such, although the profile of LBSS users now appears to be relatively equitable in terms of area deprivation, it is possible that it is far less equitable in terms of measures such as education or social class. On the other hand, we have no strong reason to expect any measurement error or ecological bias to operate differentially over time, which suggests these limitations may be less important with respect to our primary aim of examining the impact of changes to LBSS upon the composition of its users. It is also reassuring to note that another recent evaluation of the socio-economic patterning of transport use (including cycling) in England reported very similar findings between analyses using household income versus area deprivation (Goodman, 2013). Nevertheless, for a deeper and more robust understanding of the profile of LBSS users we believe that one would need to employ alternative approaches such as detailed surveys of individual users, perhaps combined with some qualitative work. Such work might also allow one to examine area-level differences in more depth - for example, between areas which are both highly-deprived in terms of income but which differ in their land-use patterns, ethnic composition or local cycling cultures,

\section{Conclusion}

Making cycling an attractive option for a wide range of the population is a key policy aim of the current cycling strategy for London (Greater London Authority, 2013), and achieving this aim would be expected to help maximise the potential benefits of cycling for health and health equity (Marmot, 2010; Woodcock et al., 2014). Among LBSS users, women and residents of poorer areas remain under-represented, partly reflecting LBSS use by affluent, male commuters from outside London. Nevertheless, the scheme has become more equitable over time, with the introduction of casual use encouraging women to use the scheme, and with the eastern extension increasing the share of trips made by residents in poorer areas. These positive developments appear, however, to have been partly offset by the recent doubling of LBSS prices. The experience of London therefore suggests that making BSS available for different types of use, in both rich and poor areas, and at competitive prices are all important ingredients in maximising a scheme's potential to deliver benefits in an equitable manner.

\section{Conflict of interest}

None

\section{Acknowledgements}

AG contributed to this paper while funded by a National Institute for Health Research (NIHR) post-doctoral fellowship. The views expressed here are those of the authors and do not necessarily reflect those of the NIHR, Department for Health or Transport for London. We are grateful to Eleanor Stanhope and colleagues at Transport for London for 
facilitating our access to LBSS data, and to Oliver O'Brien at University College London for helpful comments and advice.

\section{$\underline{\text { References }}$}

Annual Population Survey, 2013. Annual Population Survey commuter flows, local authorities in Great Britain, 2010 and 2011; accessed 29/07/2013 from http://www.ons.gov.uk/ons/rel/regional-trends/area-based-analysis/commutingpatterns-from-the-annual-population-survey--local-authorities--2010-and-2011/apscommuting-data.zip.

Beecham, R., Wood, J., 2014. Exploring gendered cycling behaviours within a largescale behavioural dataset. Transportation Planning and Technology 37, 83-97.

Beenackers, M.A., Kamphuis, C.B., Giskes, K., Brug, J., Kunst, A.E., Burdorf, A., van Lenthe, F.J., 2012. Socioeconomic inequalities in occupational, leisure-time, and transport related physical activity among European adults: A systematic review. Int J Behav Nutr Phys Act 9, 116.

DCLG, 2011. The English Indices of Deprivation 2010. Department for Communities and Local Government London.

de Hartog, J., Boogaard, H., Nijland, H., Hoek, G., 2010. Do the health benefits of cycling outweigh the risks? Environ Health Perspect 118, 1109-1116.

Fischer, C., Sanchez, C., Pittman, M., Milzman, D., Volz, K., Huang, H., Gautam, S., Sanchez, L., 2012. Prevalence of bicycle helmet use by users of public bikeshare programs. Ann Emerg Med 6, 228-231.

Fishman, E., Washington, S., Haworth, N., 2013. Bike share: a synthesis of the literature. Transport Rev 33, 148-165.

Fuller, D., Gauvin, L., Kestens, Y., Daniel, M., Fournier, M., Morency, P., Drouin, L., 2011. Use of a New Public Bicycle Share Program in Montreal, Canada. Am J Prev Med 41, 80-83.

Goodman, A., 2013. Walking, cycling and driving to work in the English and Welsh 2011 census: trends, socio-economic patterning and relevance to travel behaviour in general. Plos One 8, e71790.

Goodman, A., Brand, C., Ogilvie, D., 2012. Associations of health, physical activity and weight status with motorised travel and transport carbon dioxide emissions: a crosssectional, observational study. Environmental Health 11, 52.

Goodman, A., Green, J., Woodcock, J., 2014. The role of bicycle sharing systems in normalising the image of cycling: an observational study of London cyclists. Journal of Transport and Health 1, 5-8.

Greater London Authority, 2013. The Mayor's vision for cycling in London: An Olympic Legacy for all Londoners. Greater London Authority, London.

LDA Consulting, 2012. Capital Bikeshare 2011 Member Survey Report. LDA Consulting, Washington DC.

Lyons, G., Chatterjee, K., 2008. A human perspective on the daily commute: costs, benefits and trade-offs. Transport Rev 28, 181-198.

Maizlish, N., Woodcock, J., Co, S., Ostro, B., Fanai, A., 2013. Health co-benefits and transportation-related reductions in greenhouse gas emissions in the San Francisco Bay area. Am J Public Health 103, 703-709. 
Marmot, M., 2010. Fair society, healthy lives. A strategic review of health inequalities in England post-2010. Department of Health, London.

Meddin, R., DeMaio, P., 2013. The Bike-sharing World Map (Accessed 25/10/2013 from http://www.bikesharingworld.com/).

Nettleton, S., Green, J., In press. Thinking about changing mobility practices: how a social practice approach can help. Sociology of Health and Illness.

O'Brien, O., Cheshire, J., Batty, M., 2014. Mining Bicycle Sharing Data for Generating Insights into Sustainable Transport Systems. J Transport Geography 34, 262-273.

Ogilvie, F., Goodman, A., 2012. Inequalities in usage of a public bicycle sharing scheme: Socio-demographic predictors of uptake and usage of the London (UK) cycle hire scheme. Prev Med 55, 40-45.

Rogers, E., 1962. Diffusion of innovations. Free Press, New York.

Rogers, E., 1986. Communication Technologies: The New Media in Society. Free Press, New York.

Rojas-Rueda, D., de Nazelle, A., Tainio, M., Nieuwenhuijsen, M., 2011. The health risks and benefits of cycling in urban environments compared with car use: health impact assessment study. BMJ 343, 4521.

Rydin, Y., Bleahu, A., Davies, M., Davila, J.D., Friel, S., De Grandis, G., Groce, N., Hallal, P.C., Hamilton, I., Howden-Chapman, P., Lai, K.M., Lim, C.J., Martins, J., Osrin, D., Ridley, I., Scott, I., Taylor, M., Wilkinson, P., Wilson, J., 2012. Shaping cities for health: complexity and the planning of urban environments in the $21 \mathrm{st}$ century. Lancet 379, 2079-2108.

Steinbach, R., Green, J., Datta, J., Edwards, P., 2011. Cycling and the city: a case study of how gendered, ethnic and class identities can shape healthy transport choices. Soc Sci Med 72, 1123-1130.

The Guardian, 2011. Has London's cycle hire scheme been a capital idea?, [Published 10/07/2011, accessed 19/07/2013 from http://www.guardian.co.uk/uk/bikeblog/2011/jul/10/boris-bikes-hire-scheme-london].

Transport for London, 2011a. Travel in London, Report 4. Transport for London, London.

Transport for London, 2011b. Travel in London, supplementary report: London Travel Demand Survey (LTDS). Transport for London, London.

Virginia Tech, 2012. Capital bikeshare study: A closer look at casual users and operation. Virginia Tech, Arlington.

WHO, 2002. A physically active live through everyday transport. World Health Organisation Regional Office for Europe, Copenhagen.

Wood, J., Slingsby, A., Dykes, J., 2011. Visualizing the dynamics of London's bicycle hire scheme. Cartographica 46, 239-251.

Woodcock, J., Givoni, M., Morgan, A., 2013. Health Impact Modelling of Active Travel Visions for England and Wales using an Integrated Transport and Health Impact Modelling tool (ITHIM) PLoS One 8, e51462.

Woodcock, J., Tainio, M., Cheshire, J., O'Brien, O., Goodman, A., 2014. Modelled health impacts of the London bicycle sharing system. Bmj 348, g425.

Zaltz Austwick, M., O'Brien, O., Strano, E., Viana, M., 2013. The structure of spatial networks and communities in bicycle sharing systems. PLoS One. 8, e74685. doi: 74610.71371/journal.pone.0074685. eCollection 0072013. 